\title{
TRANSGREDIR FRONTERAS \\ nuevos espacios en la narrativa yucateca contemporanea
}

\author{
Margaret Shrimpton \\ Universidade Autónoma de Yucatán, México
}

\begin{abstract}
RESU MO
Análise da literatura produzida atualmente em Yucatán, México, a partir do ponto de vista dos estudos pós-coloniais. O ensaio discute principalmente o obra de Joaquín Bestard e de Carlos Urzáiz Jiménez, focalizando o papel dos indígenas nas narrativas e a criação de uma identidade regional que se articula com a identidade nacional.
\end{abstract}

\section{PALAVRAS - CHAVE}

literatura mexicana, Yucatán, identidade nacional, identidade regional.

\begin{abstract}
What I want to emphasise in that large and liminal image of the nation with which I began is a particular ambivalence that haunts the idea of the nation, the language of those who write of it and the lives of those who live it. It is an ambivalence that emerges from a growing awareness that, despite the certainty with which historians speak of the "origins" of nation as a sign of the "modernity" of society, the cultural temporality of the nation inscribes a much more transitional social reality.
\end{abstract}

Homi K. Bhabha (1990)

\section{Nación y REgión: espacios alternativos}

La demarcación de los límites entre regiones, subregiones y naciones se hace cada vez más difícil, en particular a partir de la reflexión sobre estas categorías en los estudios postcoloniales en la década de los setenta del siglo XX. Con las teorías postcoloniales se inició una desconstrucción de las fronteras que delimitaban los discursos canónicos, en un proceso que condujo a una nueva conceptualización de las relaciones entre nación y región. En este contexto, la relevancia de los estudios regionales - desde diversas disciplinas asume una nueva importancia: el repensar los espacios permite transgredir las fronteras y construir unos nuevos, heterogéneos y fluctuantes, desde donde desafiar los cánones y esquemas establecidos en los centros hegemónicos. A la vez, las variantes académicas del postcolonialismo reflejan la diferenciación que surge a partir de esta rearticulación de 
fronteras, que ha permitido la participación en el debate de áreas antes marginadas y excluidas del discurso.

Desde la perspectiva postcolonial, tanto Eduoard Glissant (2000) como Antonio Benítez-Rojo (1996) hacen planteamientos relevantes para áreas periféricas donde urge la tarea de repensar los límites espaciales en los discursos regionales, así como por su evaluación del papel de los construidos desde la periferia. Ambos autores proponen el concepto de mundo-caos para explicar como, desde el texto literario, se elabora un discurso diferenciado. La comunicación y el diálogo permiten transgredir las fronteras lingüísticas, culturales, étnicas y religiosas para expresar una identidad multicultural dentro de un espacio de límites fluctuantes. La teoría del caos, que explica la relación sistémica de toda situación a pesar de su complejidad y diversidad, descubre relaciones espontáneas e insospechadas entre los discursos literarios resultantes de procesos multiculturales y heterogéneos. Benítez Rojo describe la forma en que diversas identidades culturales se relacionan entre sí a partir de una dinámica común (la experiencia histórica, por ejemplo) aun cuando no hay un centro compartido (es decir, la relación es entre diferentes naciones o regiones autónomas):

There's no centre or circumference, but there are common dynamics that express themselves in a more or less regular way within the chaos and then, gradually, begin assimilating into African, European, Indoamerican and Asian contexts up to the vanishing point. ${ }^{1}$

Edouard Glissant también se opone al concepto de identidad como una categoría única y propone un sistema de identidades traslapadas y múltiples, frecuentemente conflictivas, que se articulan entre sí. La propuesta de una "poética de la relación” permite establecer correspondencias entre las distintas identidades culturales y los discursos literarios producidos en la región dentro de un proceso histórico, en vez de oponerlas, en una jerarquización distanciadora, a los hegemónicos que se construyen en los centros metropolitanos. Eduoard Glissant explica su sistema a partir del pensamiento del rizoma, propuesto por Gilles Deleuze y Felix Guattari, ${ }^{3}$ y adapta ese modelo a su "poética de la relación" para poder trascender "el otro". El sistema de Glissant incluye a, y se relaciona con, el Otro: "Rhizomatic thought is the principle behind what I call the Poetics of Relation, in which each and every identity is extended through a relationship with the Other." Tanto Glissant como Benítez-Rojo ${ }^{5}$ aportan una metodología para analizar las distintas

\footnotetext{
${ }^{1}$ BeníteZ-ROjO. The repeating island. The Caribbean and the postmodern perspective, p. 24.

${ }^{2}$ Glissant. The poetics of relation.

${ }^{3}$ Michael Dash señala que el pensamiento de Gilles Deleuze es importante en el contexto del mundo globalizado y hace resaltar las articulaciones entre la unidad y la diversidad. (DASH. The other America. Caribbean literature in a New World context, p. 151). En el marco de esta investigación el pensamiento del rizoma, o la poética de la relación, permite articular una identidad regional con otra nacional.

${ }^{4}$ Glissant. The poetics of relation, p. 11.

${ }^{5}$ Michael Dash señala las similitudes entre las dos propuestas e incluso sugiere que la popularidad del segundo hizo más accesible al primero: "[Glissant's] theories predate by about a decade a similar hypothesis developed by Benítez-Rojo, whose Repeating Island (1992) may have made Glissant's earlier Caribbean Discourse (1989; originally published 1981) more accesible." (The other America. Caribbean literature in a New World context, p. 13).
} 
identidades presentes en los textos, de manera paralela y en diálogo unas con otras. De acuerdo con su conceptualización identidad es una categoría dinámica que se entiende a partir de su relación con otras de tipo cultural y que también asume expresiones múltiples y variadas.

Desde la perspectiva postcolonial, la historia reciente de México, donde las diversas experiencias socioculturales y étnicas forman parte de un proceso que intenta construir discursos híbridos y alternativos, es paradigma de la compleja articulación entre nación y región. En las zonas fronterizas del país, como Yucatán, se acentúan aún más las complejidades de esta nueva articulación nación-región, desde donde es posible desconstruir la relación centro-periferia, que ha favorecido la dominación de un discurso nacional. La trasgresión de las fronteras establecidas entre nación/región cobra mayor relevancia en el caso de Yucatán que también articula una relación con el Caribe. Vista desde la perspectiva de las costas continentales del Caribe, la región yucateca establece "una relación dialógica" triple: la identidad nacional, la regional yucateca y la caribeña. ${ }^{6}$ Asimismo, se privilegia "una poética de relación" que permite desarticular el sistema binario que establece un centro y una periferia para el análisis de las literaturas regionales.

Aunque Yucatán comparte con otras áreas fronterizas de México (en particular la zona norte) la complejidad de una cultura híbrida, muestra particularidades que la singularizan dentro de la República Mexicana. La presencia viva de la cultura indígena milenaria en Yucatán, unida a su aislamiento geográfico con el centro y norte del país, obligan a modificar los cánones y modelos de análisis para asumir una postura alternativa que pueda abrazar las diferentes expresiones multiculturales del área de manera inclusiva.

\section{La narrativa de Joaquín Bestard: espacios multiculturales}

Kuxeb cambió cuando se le notificó que su jardín sería destruido para dar paso a un ramal que viniendo del norte, entroncaría con la carretera frente a su choza. Tiene suficiente patio atrás como para tres o cuatro jardines iguales al de adelante por lo que no hay problema, dijo el alcalde. Atrás tenía matas de caimito, ciruela chiabal, aguacate, anona polbox, ciricote y yaxché en un terreno que jamás quiso separar de los otros con albarradas interiores que le quitaran el respeto, al pensar los vecinos que él desconfiaba de ellos.

Bestard, 1987, p. 8.

La nueva mirada de Joaquín Bestard (1935-) hacia Yucatán se plasma en su obra en la creación de los entornos. Nunca antes los espacios han gozado de tanta importancia en la narrativa regional. Bestard describe con lujo de detalles la ubicación de sus textos, pero

\footnotetext{
${ }^{6} \mathrm{La}$ "condición de isla" que padece Yucatán por su aislamiento tanto físico como cultural, se expresa en una serie de mapas de 1528-1532 donde la península fue representada como isla (Mapas de Diogo de Ribeiro 1529-1532, en Antonchiw. Historia cartográfica de la Península de Yucatán, p. 98). No fue hasta 1959 que Yucatán se conectó por ferrocarril al centro de la República Mexicana; antes, el viaje se realizó por barco de Progreso a Veracruz (travesando el Golfo), para continuar luego en tren a la Capital.
} 
su propósito no es solamente hacer que el lector palpe con todos sus sentidos los paisajes tropicales de Yucatán, sino que, además, la vida de los yucatecos va entretejida con esos paisajes, en una complicada cosmovisión regional que determina la creación de un texto híbrido.

El tigre con ojos de jade (1966) y De la misma herida (1985) son dos obras de este prolífico escritor yucateco que servirán como paradigmas para explicar la construcción de la identidad regional en su narrativa. La primera novela aísla al lector en una sola parte del espacio yucateco - el monte - creando una imagen de Yucatán, rural y campesina. La segunda, escrita veinte años después, cuestiona el regionalismo y demuestra interés por descubrir las distintas capas esa identidad. Ambas novelas, sin embargo, plantean el carácter regional de Yucatán de una manera particular, y el lenguaje desempeña un papel fundamental como medio para la des-construcción de los dualismos presentes en la literatura anterior.

Desde la primera novela, Un tigre con ojos de jade, publicada en la Ciudad de México en 1966, el escritor yucateco demostrará su capacidad de ir en contra de las tendencias de la capital. La diégesis determina un espacio cerrado que domina y lo absorbe todo, excluyéndolo e incomunicándolo del mundo que pueda existir afuera. Un estilo "asfixiante" conduce a esto. El texto empieza con minúscula, in medias res, como si ya hubiese comenzado la historia. Esta técnica marca un cronotopo particular pues la acción es encerrada en el monte, mientras que el tiempo no tiene límites: el mundo del monte es perpetuo:?

agarró el calabazo y lo llenó con agua que extrajo de una tinaja de barro, decorado con flores y hojas en relieve del mismo material cocido; una vela parpadeaba de flojera incurable, sobre la mesa de patas reforzadas, abandonada en el rincón; de un vistazo examinó el techo de huano seco y caminó hasta las paredes impregnada de sombras revueltas, de donde descolgó el rifle, mohoso y empolvado; a sus pies, un perro flaco y arrugado, movía el rabo en nerviosas sacudidas... ${ }^{8}$

La detallada descripción del monte responde directamente a las percepciones del personaje central (El Hombre) y de su perro, ya que el texto juega con la doble perspectiva de un narrador no marcado, con una focalización interna. Esto sitúa al lector en el lugar y el momento de los hechos y de ese modo reduce radicalmente la distancia entre la ficción y la realidad.

Detrás del hombre, iba el perro, por momentos el animal correteaba para ponerse delante, sin dejar de girar hacia atrás la cabeza en actitud sumisa; quizás para interrogar al amo que parecía no hacerle caso y seguía la vereda sin tener que adivinar su antojos; cosa que despertaba por ratos la infinita indiferencia del perro, que un poco pendenciero, se detiene y queda rezagado a propósito; ya ventea un turix de alas transparentes y lunares morados, mordisquea las ramas del sak-baké o como ahora, se entretiene en dar de volteretas sobre el zacate escaso, sin perder de vista al hombre iBicho, ven!; la voz, la voz del amo, era como darle renovada vida al perro; ${ }^{9}$

\footnotetext{
${ }^{7}$ Esta novela fue denominada "irrespirable", por la crítica periodística nacional (El Universal, México, D.F), por carecer de un uso gramatical convencional. Esta no-gramaticalidad consiste en el empleo de comas y punto y coma, exclusivamente, prescindiendo del punto y aparte con la excepción del último del libro; así, la novela es una sola frase, o un solo pensamiento, interminable.

${ }^{8}$ Bestard. Balada de la Mérida Antigua, p. 7. Las citas son del manuscrito original, inédito. La versión publicada en 1966 por Costa Amic fue corregida para excluir todos los vocablos y expresiones regionales. El autor desea que se llegue a conocer la original, con la inclusión nuevamente de los mayismos en el texto.
}

${ }^{9}$ Bestard. Balada de la Mérida Antigua, p. 8. 
Fundamentales para la descripción del entorno son el lenguaje y las figuras empleadas, que nacen de un profundo conocimiento del campo y del monte yucatecos, y de la forma de vida de los campesinos y cazadores. Se combinan metáforas inspiradas en la observación de la naturaleza y en la cosmovisión de los mayas actuales, quienes otorgan poderes diversos y propiedades específicas a distintos fenómenos naturales:

el viejo entrecerró los ojos y renovó el aliento en la caverna de la boca olorosa a sascab, jul y olvido, se encogió de hombros y siguió la vereda como si nada sucediera, porque al monte hay que mostrarle indiferencia y jamás temor, para que sus criaturas infernales no se multipliquen o se amontonen en la espalda de los caminantes y abusen; se alejan, hombre y perro, muy a su modo... ${ }^{10}$

De este modo, las creencias y la representación maya del universo, tan distintas al modo de pensar y actuar no-indígena, no son recreadas aquí como el "otro", sino combinadas en complicadas metáforas como núcleo del texto. Se destina un lugar primordial al pensamiento maya en el discurso, y no lo separa como anécdota, cuento o tradición. El campesino y el perro, el monte, el venado y el tigre enlazan el mundo natural con el mítico. Se podría postular entonces que la identidad yucateca en este texto corresponde exclusivamente al mundo maya actual, que tiene su pasado en su presente - en el tigre con ojos de jade.

Para Bestard, sin embargo, la presencia latente del "otro" mundo (en este caso noindígena), ausente en aquella primera novela, se convierte en tema fundamental en su posterior obra, De la misma herida (1985), y en numerosos cuentos escritos en los ochenta y noventa, pues todas las caras de la sociedad tienen que interrelacionarse. ${ }^{11}$ En su paulatina toma de conciencia, los conflictos y tensiones dentro de la sociedad yucateca necesariamente exigen estar en primer plano.

En su novela De la misma herida (1985) es notable el enfrentamiento entre dos modos de pensar. Por un lado, el del indígena; y por el otro, el del no-indígena. Los dos se enfrentan, pero también se combinan (aunque incómodamente) en el inevitable mestizaje que vino "a complicar las cosas de nuestra tierra" ${ }^{2}$. Mientras es evidente la confrontación entre los dos mundos, también es notable la manera en que el discurso del indígena subvierte el del no indígena y ocupa su lugar. Esto se logra en diversos planos en la novela, por un cuidadoso manejo del lenguaje - utilizando un léxico maya yucateco - y, estructuralmente, por la forma en que se entretejen las referencias a la cultura tradicional (maya yucateca) y a la moderna (citadina). El lenguaje funge para Bestard como el medio para expresar los conflictos y los problemas inherentes al complejo mundo del Yucatán mestizo y moderno.

La ausencia de comillas para señalar los vocablos regionales apoya la búsqueda de lo que se podría determinar como un texto multicultural o transculturado: se evita estigmatizar la cultura autóctona y relegar el habla regional a un segundo plano. Bestard otorga un papel fundamental al lenguaje regional, no solamente en términos de su léxico, sino como

\footnotetext{
${ }^{10}$ Bestard. Balada de la Mérida Antigua, p. 13.

${ }^{11}$ Ver: Joaquín Bestard, Los tiempos dorados de Tránsito, Maldonado Editores, Yucatán, 1985; y Doce cuentos de Beyhaulé (Ed. Lee Daniel), York Press, Fredericton, N.B. Canadá, 1994; "Sembrar la semilla en el tiempo", en Signos, n. 4, Yucatán, 1993; "El camino de los álamos" en Entorno, 1990, El cuello del jaguar, UADY, 2000.

${ }^{12}$ Bestard. De la misma herida, p. 49.
} 
transmisor de la tradición oral. Teje magistralmente el mundo de la oralidad con el del texto escrito, que es su novela. Logra transmitir al lector la idea de que las "tradiciones" no tienen que ser recopiladas en antologías como la "otra" cultura, sino que forman parte de la vida misma de los habitantes de la zona.

Entremezclados en las páginas de De la misma herida, se encuentran el paisaje típicamente yucateco, poblado por sus árboles, pájaros, sol y piedras; las referencias a sus leyendas y tradiciones; el léxico del español yucateco e incluso vocablos mayas. Estos elementos no participan en la novela unilateralmente, sino que van tejidos con otra intención: conforman el espacio descriptivo, pero además remiten a una forma de vida y a una serie de costumbres y creencias arraigadas en la tierra y su gente.

Así, por ejemplo, a lo largo de la novela encontramos marcadores del entorno que nos ubican en un espacio maya yucateco, vinculados a historias narradas desde el punto de vista de los indígenas y mestizos. Desde esta perspectiva alterna, el lector acepta un mundo donde hormigas rojas se comen a las mujeres ${ }^{13}$; donde los murciélagos se comunican con las personas ${ }^{14}$; y donde la naturaleza determina el comportamiento de la gente, como, por ejemplo, en la fusión de la abuela (Chich) con el aire, la noche o la sombra del tamarindo ${ }^{15}$.

A diferencia de El Tigre con ojos de jade, novela que se limita al monte, esta otra presenta varios espacios que se interrelacionan: existe una especie de diálogo entre el mundo y los espacios indígena, blanco y mestizo. El personaje de la abuela "Chich" establece las fronteras, marca las diferencias y asume el derecho a romperlas. "Chich" es también un marcador del entorno, delimitando los mundos de la novela, y es retratada siempre como parte de la naturaleza, enfatizando tanto su pertenencia al lugar y permanencia en él, como la armonía entre ella y la naturaleza misma: "Tal vez algún día fui arbusto, flor, abeja, golondrina, hoja que viajó en el viento o nube que se desahogó en la lluvia. Doy gracias por ser hoy mujer y poder juzgarlo" ${ }^{\prime 16}$.

La figura de la Chich no es idealizada en la novela, pero sí constantemente vinculada con la naturaleza. Bestard logra desmitificar a Chich porque es una figura sumamente importante - como abuela - en la vida cotidiana y familiar de la región. Apela a su vejez, a su sabiduría y a su sentido de pertenencia para reiterar su relación con el lugar. Más que una idealización, la Chich resulta ser un símbolo de la permanencia del maya yucateco: ella representa el origen - el pasado en el presente, y así mismo su importancia como "mujer capaz de juzgar [sic]" y su presencia como el aire o el viento. La simbolización de Chich se logra cabalmente a través de un complejo tejido de su vida en el pueblo con leyendas provenientes de la tradición oral, y así queda clara la relevancia de las creencias en la vida cotidiana de los pueblos yucatecos.

Los diferentes niveles del texto marcan los cambios de posición de la Chich en relación con los actores del mundo blanco - su amo, Don Pedro Bech, y su familia. El narrador no marcado describe a la Chich como una anciana quejosa, pero satisfecha de haber

\footnotetext{
${ }^{13}$ Bestard. De la misma herida, p. 19.

${ }^{14}$ Bestard. De la misma herida, p. 21.

${ }^{15}$ Bestard. De la misma herida, p. 34.

${ }^{16}$ Bestard. De la misma herida, p. 32-33.
} 
consolidado una posición en la casa del amo para dar seguridad al futuro de sus nietos ${ }^{17}$. Sin embargo, el narrador en tercera persona se desliza hacia la voz de la Chich, para privilegiar no una situación de seguridad, sino una de diferencia: "Mi yerno trabaja para Don Félix. [...] ¿Por qué mis nietos no pueden salir iguales de aprovechados?"18. Los constantes movimientos del plano del narrador al plano de la Chich marcan los dos mundos - blanco e indígena - y diferencian sus maneras de pensar, sentir y actuar. Es notable que la voz narrativa no asuma la mirada de los actores blancos, quienes solamente tienen voz en sus diálogos. De esta manera la mirada del texto es focalizada desde la perspectiva alternativa de la Chich.

Don Pedro Bech se mantiene distanciado de la Chich, y se separa de su mundo. Cuestiona sus creencias, y no acepta su verosimilitud. Don Pedro establece dos mundos: el suyo, y el fantasioso de la Chich. La estrategia narrativa empleada indica claramente, por ejemplo, que lo que es leyenda para el no-indígena, es simplemente la verdadera vida para la Chich y su familia, y son experiencias de las que es necesario hablar para mantenerlas vivas:

La noche, la vereda, el aire, la piedra o la sombra del tamarindo, eso será Chich. Hizo una pausa antes de tragar saliva y retener las lágrimas, sentía que el llanto le caminaba por dentro sin encontrar salida y prosiguió con notable esfuerzo que motivó el silencio respetuoso del Bech mayor: donde está el canto de la xcoquita, donde la yuya vestida de naranja y negro teja su nido colgante y el gavilán remonte el techo del mundo, desde ahí ya lo creo que vigilaré. [....]

- Chich, pienso que después de todo eres una gran fantasiosa.

-Quién sabe, don Pedro, nunca lo he sabido, se inclinó más sobre los pasitos temblorosos. Lo que sé es que estoy vieja y me basta. ${ }^{19}$

Para la Chich, sus creencias son su realidad; ella vive día a día y sus verdades son tales como: "estoy vieja y me basta". La tradición oral, la memoria, los mitos, dejan de ser "diferente", "de la imaginación, o "fantasiosos" para convertirse en marcadores importantes del entorno yucateco, que Bestard recrea a partir de esta obra, espacio creado a partir de la cosmovisión indígena, no occidental, denominado por Lienhard, alternativo ${ }^{20}$. El papel de la Chich y sus descendientes - las mujeres que narran las historias íntimas de la novela es importante en relación con el medio ambiente que el autor recrea. Son mujeres, indígenas y mestizas, inmersas en una vida que los "dueños del pueblo" han tratado de ocultar. Son maestras encargadas por el autor de narrar "la verdadera historia", la vida que se vive "en carne propia" ${ }^{21}$.

En posteriores novelas Bestard explora las complejidades del mestizaje, no limitándose simplemente al mestizo de la mezcla del español con el indígena, sino contemplando una realidad social yucateca más amplia, en donde es necesario hablar de chinos, coreanos,

\footnotetext{
${ }^{17}$ Bestard. De la misma herida, p. 25.

${ }^{18}$ Bestard. De la misma herida, p. 25.

${ }^{19}$ Bestard. De la misma herida, p. 34.

${ }^{20}$ Lienhard. La voz y su huella.

${ }^{21}$ Bestard. De la misma herida, p. 109.
} 
cubanos y libaneses. ${ }^{22}$ En una de sus más recientes novelas, ${ }^{23}$ una épica histórica sobre la Guerra de Castas en Yucatán (1847), Bestard logra un emotivo testimonio del pueblo yucateco. Los constantes cambios en la perspectiva narrativa otorgan la voz a distintos personajes relacionados con una variedad de entornos, fundiendo en el texto barreras que se erigen todavía en la sociedad moderna.

Entrar al espacio narrativo que crea Joaquín Bestard en El cuello del jaguar (2000), obliga a "un cambio de piel”; la mirada es otra, y los espejos dan imágenes yuxtapuestas y traslapadas de "nuestro" mundo. "¿En qué consiste nuestra blancura? Acaso es algo igual a un lienzo jamás manchado?"24. La pregunta es provocativa. Su preocupación central está ligada a constantes cambios de perspectiva que marcan los diferentes mundos, en un proceso narrativo que se acerca y se aleja de los espacios creados.

La voz narrativa está, al principio, inmersa en el mundo criollo; en particular es la voz de las mujeres criollas, testigos impotentes de la destrucción de su mundo por la guerra que las rodea. Las mujeres criollas tratan de seguir su vida cotidiana de tertulias, fiestas y reuniones, donde comentan las más recientes modas y donde lo más importante es quién se casa con quién, todo, mientras gozan de pan blanco (de trigo) y chocolate caliente. La frivolidad de sus acciones y su aislamiento en un mundo y una tierra que realmente desconocen salen a relucir en los recursos empleados por el autor. Es de destacar que la autoridad narrativa - la voz de ellas - pronto pierde el control, y cede a otros discursos.

En primer lugar, el recurrir a las creencias del mundo maya ante los primeros rumores de quemas e incendios, por ejemplo, sirve a las mujeres para aliviar sus temores. La voz criolla es minada paulatinamente: lo maya empieza a vincularse con la seguridad y el sosiego, y el mundo criollo con la inseguridad y el temor. El espacio criollo es invadido por el espacio maya.

En segundo lugar, se intercalan cartas de la Guerra de Castas (algunas de ellas originales y otras que son creaciones del autor) y de nuevo la voz de las criollas cede ante los testimonios de diversos testigos y actores de la guerra - capitanes criollos, líderes y mártires indígenas, soldados y mártires criollos. Esta mezcla de fuentes cambia los parámetros del texto y permite al autor acentuar las estrategias narrativas alternativas. A las fuentes escritas se agregan las cartas que encuentran las esposas criollas, quienes pasan una noche en vela leyéndolas en voz alta. Estas "voces" nuevas resultan ser demasiado poderosas para las mujeres, quienes se rinden frente al nuevo mundo que descubrieron: "- Son muchas noticias, dijo doña Mimí. Demasiadas noticias para una sola madrugada." ${ }^{25}$. Así, la autoridad narrativa se encuentra cada vez más dispersa, y la razón y la verdad en muchas voces distintas que describen acciones diferentes en espacios desconocidos.

\footnotetext{
${ }^{22}$ Ver: Cuentos de Beyhaulé. Doce cuentos de Joaquín Bestard Vásquez, Edición, compilación, introducción y glosario por Lee A. Daniel (1994).; Ocasos de un mar de cobre, Joaquín Bestard, UADY, Mérida, Yucatán 1992. El cuello del jaguar, UADY, 2000; Balada de la Mérida Antigua, Ayuntamiento de Mérida, Yucatán, 2000.

${ }^{23}$ Bestard, El cuello del jaguar.

${ }^{24}$ Bestard, El cuello del jaguar, p. 191.

${ }^{25}$ Bestard, El cuello del jaguar, p. 136.
} 
En la segunda parte de la novela, ésta se apropia de otros discursos más, para lograr la construcción del texto alternativo. Se insertan dos "eslabones", que son: una obra teatral de un acto y doce misterios. En ambos casos, el discurso busca su autoridad en la voz viva - del teatro y de la tradición oral - y así el texto recurre a espacios "alternativos" no concretos. El avance de Doña Carmelita (personaje principal) por los doce misterios es como si fuera un rito de paso: ${ }^{26}$ en este caso, es previo a su alumbramiento de un bebé mestizo, como consecuencia de su violación después de la destrucción y saqueo de Dzonot, pueblo donde vivía.

La fragmentación del texto simboliza el colapso del mundo criollo: la destrucción de sus pueblos y ciudades, la pérdida de sus pertenencias y valores materiales, de hijos y maridos, sin las que el mundo pierde su valor. De la misma manera, el discurso criollo cede su autoridad al discurso maya. Mientras más avanza la obra más crece el universo maya el idioma, las referencias culturales, los personajes, la temporalidad y los espacios naturales. Empieza la fusión de los mundos, y el discurso maya asume el lugar del criollo. Las leyendas y costumbres dejan de ser curiosidades para hacerse trascendentales por su lógica, orden natural y verdad.

Este cambio paulatino del texto queda ejemplificado en la relación entre dos de los personajes principales: la criolla Doña Carmelita y su fiel sirvienta maya, Nanachichí, la que asume un papel más importante en la segunda parte de la novela, y aunque nunca goza de una voz activa en la obra, su presencia silenciosa adquiere poderes comunicativos mayores: "Así Nanachichí fue primera en enterarse de lo ocurrido en Valladolid y la forma como se abandonó la ciudad. Pero en vista de que muchas no lo creerían y de contarlo ella, aumentaría el rencor que otras le mostraban, prefirió quedarse callada" 27.

Este contraste en la novela es uno de sus logros más significativos. Por un lado, la falta de comunicación y la fragmentación del mundo criollo, a pesar de tener el control de la palabra; y por otro, la participación sensible y profunda del universo maya, que sin pronunciar palabra asume un poder discursivo mayor, con el despliegue de metáforas que unen los actores con su universo. Al final, el espacio o el entorno maya es el que establece el orden y la lógica.

\section{De la nOSTAlgia a la transgresión: espacios uRbanOS}

Pero qué duda cabe, por estas mis venas, quiéralo o no, corre sangre yucateca o, si se prefiere, peninsular, es decir, de la hermana República de Yucatán, como reza la irónica expresión. Por ambas partes desciendo de una vieja estirpe en donde lo español y lo maya se mezclan de tal modo caprichoso que mis orígenes se pierden en los laberintos del espacio y el tiempo, del azar y del amor. [...] En Mérida podemos encontrar desde lo más sublime hasta lo más grotesco; resulta sin duda, una ciudad inagotable.

Hernán Lara Zavala, 1998.

\footnotetext{
${ }^{26}$ Término antropológico: "Ritos de paso, ceremonias que marcan el paso de una fase de la vida o de un estatus social a otro." El término fue introducido por el antropólogo belga, Arnold van Gennep. (Enciclopedia Microsoft Encarta 2000).
}

${ }^{27}$ Bestard, El cuello del jaguar, p. 229. 
Las calles yucatecas, descritas en la novelística del siglo XIX con la precisión de un cartógrafo, cobran vida en el XX con la adición de detalles que se refieren más a su uso, a la gente que las habita, trabaja y juega en ellas; y menos a su ubicación en el mapa de la ciudad. Este recurso permite al escritor plasmar el sabor, y hasta el olor yucatecos, incorporando al texto las expresiones de las pregoneras, tan características de la ciudad, y a la vez recordando las frutas y otros productos típicos de la zona. El siguiente fragmento de la novela Evaristo (1977) del escritor Carlos Urzáiz Jiménez, ilustra este punto:

La música del carrusel y la rueda, los timbres de los cines anunciando función, el volverío de los participantes, los gritos de los vendedores de variadas mercancías y los pregones de la lotería campechana integran el ruido.

-iEl sol con sus rayos quema! iLa dama encopetada! iEl que le cantó a San Pedro!

-iLotería con el gallo. Lotería!

El olor es de frutas y en especial de nancen que tiene el tufo penetrante y está en su época ... Extrañamente esta masa humana mezclada, expuesta al calor de la tierra, casi no hiede ... Las mujeres huelen a jabón de Castilla o Heno de Pravia y a polvos de arroz. Los hombres discretamente a tabaco. ${ }^{28}$

Le confiere así una marca esencialmente meridana al texto, que una vez más indica la separación de este lugar del centro de la República: "A la Ciudad de México, capital de su país no la tiene en cuenta y dice que es un rancho llena de charros, chinas poblanas, diputados bigotudos, chinches y piojos". ${ }^{29}$

El mismo autor, en el prólogo a un libro de cuentos de otro escritor yucateco, ${ }^{30}$ afirma este carácter "distinto" de Mérida y de los yucatecos. Dos veces en apenas cuatro páginas repite el famoso dicho de éstos sobre su tierra "Yucatán, el país que no se parece a otro". Lo acompaña y justifica con la anécdota de un niño que visita el lugar y piensa que ya no está en México, ${ }^{31}$ y en más de una ocasión señala como rasgo determinante el habla particular de los yucatecos: una combinación de "arcaísmos, mayismos y voces caribeñas" (1990: prólogo). Sin embargo, en la opinión del prologuista es, al final, además del habla yucateca, lo esencialmente "meridano" lo que caracteriza a los cuentos narrados en este libro:

...pero no se necesita ni siquiera esto (el habla, sic.) para sentir el sabor del coco y la guanábana en el idioma saturado de giros vernáculos inconfundibles y de nombres de esquinas y de establecimientos que sólo pueden ser de aquí y tienen un inefable encanto. ${ }^{32}$

Es evidente la nostalgia en estas palabras que añoran tiempos pasados y recuerdan elementos físicos de la ciudad y las costumbres antiguas para simbolizar lo diferente de Mérida y los yucatecos; una distinción especialmente importante para la burguesía meridana.

\footnotetext{
${ }^{28}$ UrzÁiz JimÉNEZ. Evaristo. Historia de un soltero con familia, p. 66.

${ }^{29}$ UrzÁrz JimÉnez. Evaristo. Historia de un soltero con familia, p. 42.

30 Ver. Felipe Escalante Ruz, Emociones del Recuerdo.

31 "Un eminente intelectual yucateco radicado desde hace mucho tiempo en la metrópoli, me decía que en una de sus visitas al terruño, acompañado de sus nietos, uno de ellos le preguntó al contemplar por primera vez la ciudad de Mérida: "Abuelito, itodavía estamos en México?" (Urzaíz jimÉnEz en Escalante Ruz. Emociones del recuerdo, Prólogo).

32 Urzáiz jimÉnez, en Escalante Ruz. Emociones del recuerdo, Prólogo).
} 
En Balada de la Mérida antigua (2000), Joaquín Bestard mira con ojos nostálgicos a la ciudad de antaño, continuando temáticamente el camino iniciado por las obras arriba señaladas. En ellas, sus autores recuerdan con cariño diversos aspectos de la vida meridana - el ritual del café, el ruido de los marchantes pregonando sus productos, la belleza de la ciudad colonial con sus casonas de patio interno y otro grande atrás, y la mención de calles, plazas, parques y edificios, algunos ya desaparecidos. Pero Balada de la Mérida antigua mira con otros ojos el presente y el futuro, y observa una Mérida distinta, antigua también en el sentido de ruina. Bestard señala de este modo su ruptura con la tradición anterior, y su canto a la ciudad y su sociedad actual es crítico y profundo.

El entorno en esta novela es diferente al presentado en las obras anteriores. Las dos caras de Mérida - la soñada del pasado y la de hoy - muestran las contradicciones inherentes a nuestra sociedad. En el seno de la familia retratada, observamos la lucha generacional entre el hijo (Escolástico) y su madre (Doña Sara), quienes habitan una vieja casona en el centro histórico de la ciudad; aquella derrumba poco a poco alrededor de la madre y de su hijo, tal como los vestigios de la vida antigua y de las tradiciones. Sin embargo, la relación de Escolástico y Doña Sara se ve complicada por la presencia de x-Pet, la criada maya de Doña Sara, quien había sido nodriza del niño Escolástico. El texto las presenta como dos madres, señalando así los dos orígenes inextricables de Escolástico: el blanco criollo y el indígena maya. De esta manera, Bestard transporta del campo a la ciudad las temáticas constantes de su obra, y logra una nueva trasgresión de fronteras.

Estas dos fuentes de vida - la criolla y la maya - se transportan al texto en calidad de fuentes históricas. La narración tiene un alto grado de intertextualidad, al conjugar textos coloniales españoles, como La relación de las cosas de Yucatán, del obispo Landa; con textos indígenas, como Los cantares de Dzitbalché, (notas de Barrera Vásquez); y con la voz narrativa de Escolástico, quien se mueve en distintos planos en la novela - narrando su pasado, sus recuerdos, sus sueños; y su presente, en el que también intercala sus escritos periodísticos. La verdad de las historias es entonces fragmentada en las voces narrativas señaladas: la española, la indígena y la mestiza. Así, al final de la novela Escolástico le aclara a su madre que existen tres verdades: "Tres, mamá. La tuya, la de x-Pet y la mía”33.

No obstante, la concepción matemática del triángulo no resuelve los problemas ni las contradicciones, como tampoco el mestizaje sirve como receta para curar las heridas profundas de la sociedad. Martín Lienhard, citando fuentes de principios del siglo XVII, nos recuerda que el término mestizo surgió de la noción de Quimera, que era un: "monstruo, que echa llamas de fuego por la boca y tiene cabeça y cuello de león, el vientre de cabra y la cola de dragón" ${ }^{34}$.

Lejos de ser armonioso, Lienhard señala "el carácter altamente conflictivo de la mixtura que provocó, en la esfera cultural, la coexistencia colonial entre europeos e indios" 35 .

\footnotetext{
${ }^{33}$ Bestard. Balada de la Mérida Antigua, p. 252.

${ }^{34}$ LienhARD. La voz y su huella, p. 132-133.

${ }^{35}$ Lienhard. La voz y su huella, p. 133.
} 
La novela, entonces, explora las consecuencias de esa mezcla étnica en la Mérida actual, en todas las esferas de la vida cotidiana.

Bestard destaca las contradicciones y la hipocresía de la moderna sociedad tecnológica regida socialmente por valores coloniales, a través de códigos sociales que dictan que las amistades se dan según el apellido y abolengo y que la vida familiar resulta imposible sin "el servicio". Doña Sara y x-Pet, su criada, aparecen en la novela como dos caras de la misma moneda: su convivencia es necesaria, pero el desprecio de cada una hacia el mundo de la otra es también inevitable. Escolástico narra la mutua dependencia de Doña Sara y x-Pet, sus dos madres; pero x-Pet, en uno de sus pocos diálogos, le aclara que hay un mundo más allá de la vieja casona que los encierra, y que ella mantiene su independencia y su resistencia ante la cultura blanca:

Hablas como mamá, $\mathrm{x}$-Pet. Parece una burla soltar las mismas palabras colocadas por ella en tu boca.

Tu alma es la que trepa a la ceiba y yo la cuido abajo con tal de impedir que caiga.

Aprendiste mucho, $\mathrm{x}$-Pet, de tu patrona.

Más traje de Beyhaulé, mi-amor.

Pero si eras una chiquita.

Nosotros heredamos las cosas del abuelo o la abuela. ${ }^{36}$

Las contradicciones en torno a $\mathrm{x}$-Pet son innumerables. Su presencia física en la novela es predominante y, aunque en menor grado que en otras novelas de Bestard, su mundo le roba espacio al discurso criollo. Sus pasos silenciosos y "calculadores" (en palabras de Escolástico) lo sorprenden y vigilan constantemente. A su mujer, Eurinidice, le inspira temor y pone de cabeza su mundo:

No sé por qué. Ni el más mínimo indicio tengo para sospechar. Se ha portado muy bien. Tampoco demasiado servicial, porque percibe el rechazo constante en mis miradas. Le temo, y lo sabe. Su olor, a guayaba io ciricote?, yerbabuena io apazote? Y tal vez a ruda. Su aroma parece adormecerme y ponerme la mente en blanco. Me hace sentir en un subibaja hasta perder el aliento. Como si estuviera en un bote y remara en dirección a un isla cada vez más lejana. Yo la quiero fuera de mis cosas y de mí. Me llena de presentimientos a desastre próximo. Yo veo en sus ojos un millón de llamitas y cada llamita se vuelve un presagio. [... ] Yo represento el futuro, aquí en la casa. Ella, en cambio, el pasado aún a flote, sin desvanecerse. ${ }^{37}$

El pasado y el presente se encuentran, entonces, inextricablemente enredados, pero cada uno con su propia voz.

\section{CONSIDERACIONES FINALES}

Es importante hacer resaltar que el papel del indígena y de su entorno en la narrativa ha modificado paulatinamente el proceso de formación de la literatura regional en Yucatán. El discurso literario en estos textos muestra la construcción de una identidad regional que se define, precisamente, a partir de las diferencias presentes, y de un collage de seres que

\footnotetext{
${ }^{36}$ BeStARD. El cuello del jaguar, p. 252.

${ }^{37}$ Bestard. El cuello del jaguar, p. 123.
} 
habitan ahí, sea en la hacienda, en el pueblo o en la ciudad. Esto se traduce en una identidad regional múltiple:

Señalar las diferencias significativas y ahondar en las similitudes donde las hay, entre el mundo capitalino y el provinciano, el rural y el citadino, el regionalista y el latinoamericano, sin olvidar que Yucatán, asiento de la cultura Maya, mira hacia el Caribe y tiene sus raíces en el norte de Centroamérica, es simplemente algo único y maravilloso. ${ }^{38}$

Los escritores de hoy se dedican a la libre tarea de inventar y recrear los mundos que necesitan, para proporcionar una imagen de Yucatán multicultural: una región que se abre a un espacio constantemente en cambio. Esta narrativa no se inclina exclusivamente hacia una identidad regional maya, ni tampoco española: se crea en un espacio híbrido que desconstruye las fronteras entre los establecidos (el blanco y el indígena). Este último no solo es rural, sino también urbano porque el indígena se mueve en los dos planos. Los textos emplean recursos alternativos que dan lugar a nuevos modelos literarios y permiten una relectura de la cultura regional, que a su vez conduce a una reubicación de la cultura maya en los espacios multiculturales de la región y de la nación.

Al elegir estrategias alternativas para producir un discurso polifónico e híbrido, los escritores yucatecos contemporáneos demuestran que la cultura regional (a partir de su literatura, por ejemplo) es capaz no solamente de incursionar en, y formar parte de la cultura nacional, sino que al lograrlo exige una rearticulación de las normas que controlan los límites de los espacios. En este contexto, la reivindicación de las literaturas regionales y la legitimación de sus escritores modifican el canon nacional para proyectarlos como valores propios y relevantes, tanto regionales como nacionales y derribar las fronteras de la "otredad".

Es importante señalar que en la medida en que se valore el discurso regional desde su particularidad (el yucateco, por ejemplo) nos conducirá a una reevaluación de la relación discurso nacional/discursos regionales y a preguntarnos hasta qué punto México asimilará la rearticulación de fronteras y de límites que esta relectura implica. Esta consideración cobra importancia en el contexto de un México multicultural y plurilingüe y ofrece interpretaciones relevantes para nuestra sociedad, a la vez que interrogantes.

\section{A}

\section{A B STRACT}

An analysis of the literature produced in Yucatán, México, from the perspective of poscolonial studies. The essay focuses on the writings of Joaquín Bestard and Carlos Urzáiz Jiménez, and discusses the role of the natives in the narratives as well as the creation of both a regional and a national identity.

\footnotetext{
${ }^{38}$ Joaquín Bestard, citado en el Prólogo a Cuentos de Beyhaulé, ed. Lee Daniel, 1994, p. 6.
} 


\section{KEY WORDS}

Mexican literature, Yucatán, national identity, regional identity.

\section{REFERÊNCIAS BIBLIOGRÁFICAS}

Anderson, Benedict. Imagined communities. Reflections on the origin and spread of nationalism. Revised Edition, London: Verso, 1991.

Antonchiw, M. Historia cartográfica de la Península de Yucatán, Campeche: Gobierno del Estado de Campeche, Centro de Estudios Avanzados del I.P.N., Grupo Tribasa, 1994.

Ashcroft, Bill; Griffiths, Gareth; TIFFIn, Helen. The empire writes back. Theory and practice in post-colonial literatures. London: Routledge, 1991.

Bakhtin, M. M. The dialogic imagination. 11 ${ }^{\text {th }}$ Edition. Austin: University of Texas Press, 1998.

Barnet, Miguel. La fuente viva. La Habana, Cuba: Editorial Letras Cubanas, 1998.

Benítez-Rojo, A. The repeating island. The Caribbean and the postmodern perspective. 2. Ed. Durham and London: Duke University Press, 1996.

Bestard, Joaquín. El tigre con ojos de jade. Mérida, Yucatán: Edición Manuscrita, 1966.

Bestard, Joaquín. El tigre con ojos de jade. México D.F.: Costa Amic, 1966.

Bestard, Joaquín. De la misma herida. Mérida, Yucatán: Maldonado Editores, 1985.

BestARD, Joaquín. El cuello del jaguar. Mérida, Yucatán: Universidad Autónoma de Yucatán, 2000.

Bestard, Joaquín. Balada de la Mérida Antigua. Mérida, Yucatán: Ayuntamiento de Mérida, "Colección Capital Americana de la Cultura”, 2000.

BHABHA, Homi K. Introduction: narrating the nation. In: BHABHA, Homi K. (Ed.). Nation and narration. New York: Routledge and Keegan, 1990.

DAsh, Michael. The other America. Caribbean literature in a New World context. Virginia: New World Studies, University Press of Virginia, 1998.

Escalante Ruz, Felipe. Emociones del recuerdo. Mérida, Yucatán: Universidad Autónoma de Yucatán, 1989.

García CANCLINI, Nestor. Culturas híbridas. Estrategias para entrar y salir de la modernidad. México: Grijalva, 1989.

Glissant, E. The poetics of relation. 2. ed. Chicago: University of Michigan, 2000.

Lienhard, Martin. La voz y su huella. La Habana, Cuba: Casa de las Américas, 1989.

Ligorred perramon, Francesc. U Mayaathanoob Ti Dzib. Las voces de la escritura, Mérida, Yucatán: Ediciones de la Universidad Autónoma de Yucatán, 1997.

Ortiz, Fernando. Contrapunteo cubano del tabaco y el azúcar, La Habana, Cuba: Editorial de Ciencias Sociales, 1991.

Rama, Ángel. Transculturación narrativa en América Latina, México: Siglo XXI, 1983.

Ramirez Carrillo, Luis, Historia regional de Yucatán. Perfil socioeconómico. México: Limusa Noriega Editores, Conalep/SEP, 2000.

Shrimpton, Margaret. "Yucatán en su narrativa". In: BAnsart, Andrés et al. El Caribe continental e insular en su literatura: ivasos comunicantes o fronteras?, Caracas, Venezuela: Comisión de Estudios de Posgrado, Universidad Central de Venezuela, Asociación Venezolana de Estudios del Caribe, 2001.

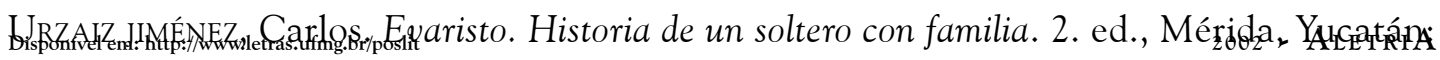
Universidad Autónoma de Yucatán, 1990. 